\title{
ORIGINAL
}

\section{The impact of one session resistance exercise on plasma adiponectin and RBP4 concentration in trained and untrained healthy young men}

\author{
Masoumeh Mansouri ${ }^{1)}$, Abasali Keshtkar ${ }^{1)}$, Shirin Hasani-Ranjbar ${ }^{1)}$, Ehsan Soleymani Far $^{2)}$, \\ Ozra Tabatabaei-Malazy ${ }^{1)}$, Kobra Omidfar ${ }^{1)}$ and Bagher Larijani ${ }^{1)}$ \\ 1) Endocrinology and Metabolism Research Institute, Tehran University of Medical Sciences, Tehran, Iran \\ 2) Physical Education and Sport Sciences, Tarbiat Moallem University, Tehran, Iran
}

\begin{abstract}
We designed this study, to investigate the predicting effect of a single resistance exercise session on serum level of RBP4 and adiponectin in trained and untrained subjects and to evaluate whether regular training may affect the response of these adipokines to exercise. Thirty four healthy young male students including 19 trained and 15 untrained participated in this study; each group was then randomly assigned to intervention and control groups. The exercise session prolonged 120 minutes intensive resistance program at 70\%-80\% of 1RM. The blood samples were collected just before the start of training program and 4 hours post exercise to evaluate concentration of adiponectin, RBP4 and CRP as well as other metabolic markers. The serum level of adiponectin, RBP4 and CRP was not significantly different between trained and untrained groups at baseline. More over four hours post exercise adipokines concentration and CRP didn't differ between groups. Adjusted regression model showed, basal adiponectin $(\beta=0.59, p=<0.001)$ and HDL cholesterol $(\beta=0.28, p=0.09)$ were the main predictors of post exercise adiponectin concentration. In addition, the basic level of RBP4 appeared to be the only predictor of after exercise RBP4 concentration $(\beta=0.46, p=0.02)$. Neither one session of high intensity resistance exercise nor long term training had predicting effect on post exercise adiponectin and RBP4 concentration in healthy young men. In the other hand, the beneficial effect of acute resistance exercise training may not be reflected by changes in adiponectin, RBP4 and CRP concentration in healthy young individual no matter they trained or untrained.
\end{abstract}

Key words: Acute resistance exercise, Adiponectin, Retinol binding protein-4, Trained, Untrained

EXERCISE training is recommended to improve long term health cardio metabolic outcomes [1-3]. One of the physiological changes responsible for health and cardio metabolic benefit of exercise could be mediated by changing the secretion of adipokines which is suggested to involve in inflammation. Adiponectin and retinol binding protein-4 (RBP4), adipose tissue derived- adipokines, are related to inflammation and cardio metabolic risk factors. Adiponectin exerts cardio protective effect [4] and inhibits signal triggering inflammation [5]. Low plasma adiponectin level appeared to have correlation with higher level of cardio metabolic risk factors [6]. In contrast, some evidence

Submitted May 26, 2011; Accepted Jul. 25, 2011 as EJ11-0046 Released online in J-STAGE as advance publication Aug.12, 2011

Correspondence to: S. Hasani- Ranjbar, Endocrinology and Metabolism Research Institute, Tehran University of Medical Sciences, Tehran, I. R. Iran, P.O. Box 14395/1179, Tehran, I.R. Iran. E-mail:sh_hasani@sina.tums.ac.ir shirinhasanir@yahoo.com shows serum level of RBP4 is increased and correlate with subclinical inflammation [7]. Moreover several studies but not all confirmed association of increased circulating RBP4 with metabolic abnormality [8-10] and cardiovascular risk factors [11]. Increasing adiponectin and decreasing RBP4 by life style change, posed the suggestion that the ability of exercise to improve cardio metabolic markers might partly be mediated by modifying the secretion of these adipokines. Several studies examining the effect of various kinds of exercise on adiponectin and RBP4 have resulted in controversial finding. The potential benefit of resistance exercise to cardio metabolic marker made resistance training (RT) to become an accepted part of programs for health. The physiological and biochemical responses to resistance exercise might be different from those resulted in response to aerobic exercise [12]. In addition little information is available on describing adiponectin and particularly rbp4 responses 
to acute resistance exercise. Thus we designed this study, to investigate whether the beneficial effect of one session of high intensity resistance exercise would be reflected by increase in anti-inflammatory adipokine and decrease in RBP4 and C-reactive protein (CRP). We hypothesized that, the basic level of these adipokines and CRP and their changes in response to one session of resistant exercise might be different in trained and untrained groups.

\section{Material and Method}

34 healthy young male students among volunteers who informed by flyers, placed on university dormitories boards were selected in this study. The volunteer's subject was asked to fill out a screening questioners regarding to life style, past medical history and physical activity to recruit eligible individual for the study. Inclusion criteria were age between 20-30 years and not to be smoker. Moreover they should be free of any kind of disease that wouldn't permit them to take part in this study such as cardiovascular, metabolic and musculoskeletal disorders. In addition those who took any medication and supplements were excluded. Since they fed in university restaurant, they had the same meals. According to training status the eligible students divided to trained including 19 healthy trained and 15 healthy untrained groups. The trained participants were physical education students and engaged in a regular resistance training program one hour, three times per week over the past ten months and untrained were those in different fields other than physical education and they had just their daily activity 10 months before starting the study. After giving required information about the details of the training program, all students assigned a written consent form to attend in the study. Protocol of the study has been approved (Code: E- 00129) by ethics committee of Endocrinology and Metabolism Research center (EMRC). The students arrived at the physical activity endocrine research center before $7.30 \mathrm{am}$ and remained till $6 \mathrm{pm}$. After serving breakfast body weight and height were measured with standard scales. Body mass index were calculated by dividing body weight $(\mathrm{kg})$ by height (meters squared). The first blood sample was drawn just before the start of training program, and then the trained and untrained were allocated to intervention and control groups by using black balanced randomization method. The final groups included experimental trained (ET), control trained (CT), experimental untrained (EU) and control untrained $(\mathrm{CU})$. The resistance training protocol consisted of four set 10-12 maximal repetition at $70 \%-80 \%$ of $1 \mathrm{RM}$ (one repetition which the person can lift) and the scheduled movements included chest press, cable lat pull down, leg press and leg extension. The rest period between sets and movement were two and three minutes respectively. The second Blood samples $(12 \mathrm{cc})$ were collected 4 hours post exercise to evaluate concentration of adiponectin and RBP4 and other metabolic markers. We measured RBP4 and adiponectin 4 hours after exercise, because these markers were included other markers which are generally accepted to be measured at this time. Samples sent to the lab immediately to be centrifuged and serum was separated and stored at -80 for next analysis. Plasma glucose (PG), total cholesterol and triglyceride were measured by commercially available enzymatic reagents (Pars Azmoon, Tehran, Iran) adapted to an Auto analyzer (Hitachi 902, Japan). High density lipoprotein cholesterol (HDL-C) and low density lipoprotein cholesterol (LDL-C) were assayed by using turbidometric method (Pars Azmoon, Tehran, Iran). Insulin was measured via ELISA using Monobind kit (Denmark), with interassay and intra- assay coefficient variation (CV) being $6.32 \%$ and $1.9 \%$ respectively. Serum RBP4 was measured using ELISA kit (AdipoGen, Seoul, Korea). The total and HMW adiponectin were also assessed using ELISA kit (Millipore, USA). The measured intra-assay (CV) RBP4 were $3.5 \%$, and the inter-assay were $7.1 \%$. The measured intra-assay $\mathrm{CV}$ for adiponectin was $7.5 \%$ and the inter-assay was $6.25 \%$. Hs-CRP was measured by ELISA using Pars Azmoon kit (Tehran, Iran) with an inter-assay $\mathrm{CV}$ of $1.7 \%$.

\section{Statistics Analysis}

All of statistical tests were performed using the SPSS statistical package v.16 for Windows (Chicago, IL, USA). Normality assumption of variables was assessed by Kolmogorov-Smirnov test and not normally distributed data were transformed to log scale (RBP4 and Insulin). To evaluate the differences for each variable between groups at base line and after training session ANOVA was used and when a significant effects was observed, the Scheffe post-hoc test, was performed to determine the status of each group. Paired $t$ test were used to determine whether statistically significant within groups differences existed 
Table 1 Clinical characteristics and metabolic markers of the participants in trained and untrained subgroups at baseline

\begin{tabular}{|c|c|c|c|c|c|}
\hline \multirow{2}{*}{ Variables } & \multicolumn{2}{|c|}{ Trained } & \multicolumn{2}{|c|}{ Untrained } & \multirow{2}{*}{$P$ value* } \\
\hline & $\mathrm{ET}(\mathrm{n}=10)$ & $\mathrm{CT}(\mathrm{n}=9)$ & $\mathrm{EU}(\mathrm{n}=8)$ & $\mathrm{CU}(\mathrm{n}=7)$ & \\
\hline Age (yr) & $22.4 \pm 1.83$ & $22 \pm 0.86$ & $21.7 \pm 0.88$ & $24.57 \pm 1.61$ & 0.002 \\
\hline BMI $\left(\mathrm{kg} / \mathrm{m}^{2}\right)$ & $23.2 \pm 1.49$ & $22.8 \pm 1.73$ & $23.2 \pm 2.71$ & $23.25 \pm 3.70$ & 0.97 \\
\hline Glucose (mg/dL) & $91.5 \pm 8.04$ & $82.33 \pm 12.33$ & $88.37 \pm 15.61$ & $84.71 \pm 8.95$ & 0.35 \\
\hline Insulin (mU/L) & $24.58 \pm 9.95$ & $21.37 \pm 6.76$ & $28.16 \pm 17.93$ & $22.00 \pm 11.83$ & 0.66 \\
\hline Triglyceride (mg/dL) & $123.6 \pm 47.3$ & $162.7 \pm 139.9$ & $172.0 \pm 81.03$ & $134.5 \pm 45.7$ & 0.62 \\
\hline Total Cholesterol (mg/dL) & $163.3 \pm 33.2$ & $155.7 \pm 30.5$ & $162.1 \pm 19.06$ & $163.0 \pm 26.9$ & 0.93 \\
\hline HDL Cholesterol (mg/dL) & $43.8 \pm 9.24$ & $41.6 \pm 6.89$ & $36.25 \pm 8.51$ & $41.71 \pm 7.34$ & 0.27 \\
\hline LDL Cholesterol (mg/dL) & $81.6 \pm 21.60$ & $76.11 \pm 17.65$ & $84.12 \pm 14.50$ & $82.71 \pm 18.59$ & 0.81 \\
\hline $\mathrm{RBP} 4(\mu \mathrm{g} / \mathrm{mL})$ & $46.48 \pm 18.1$ & $52.08 \pm 22.9$ & $54.15 \pm 10.4$ & $46.05 \pm 19.08$ & 0.75 \\
\hline Adiponectin $(\mu \mathrm{g} / \mathrm{mL})$ & $7.07 \pm 1.8$ & $5.76 \pm 2.08$ & $6.03 \pm 1.68$ & $6.06 \pm 2.86$ & 0.56 \\
\hline C-Reactive protein $(\mathrm{mg} / \mathrm{L})$ & $0.23 \pm 0.2$ & $1.02 \pm 1.5$ & $0.43 \pm 0.4$ & $0.17 \pm 0.07$ & 0.16 \\
\hline
\end{tabular}

Values are expressed as mean $\pm S D$. Differences between groups were calculated based on ANOVA test. ${ }^{*} P<0.05$ indicates significant differences between groups. ET, experimental trained; CT, control trained; EU, experimental untrained; $\mathrm{CU}$, control untrained. RBP4, retinol-binding protein-

for adipokine and other variables. Univariate linear regression analysis was used to find the relationship between RBP4 and adiponectin as dependent and other markers as independent variables. All of the predictors which related to dependent variable at significantly level $(P$ value $\leq 0.20)$ in univariate regression were selected for including multiple linear regression analysis to determine predictors affecting after exercise concentration of RBP4 and adiponectin. We used standardized $\beta$ coefficient as measure of magnitude of relationship or effect in all of linear regression models (univariate or multivariate) for any independent variable. Significance levels was set at $p<0.05$ and all of tests were determined as two sided.

\section{Results}

The baseline clinical and metabolic markers of four groups listed in Table 1. ANOVA analysis showed the serum level of blood sugar, insulin, components of lipid profile and CRP were not significantly different between four groups at baseline. Additionally there were no differences in circulating levels of RBP4 and adiponectin between groups at this stage. The only variable which was significantly different between groups was age. Using, the Scheffe post-hoc test, it was determined that control untrained (CU) group's age significantly differs from other groups. The paired $t$ test showed the serum level of RBP4 was not changed in response to acute resistance in any group. In contrast there was a significant reduction in adiponectin concentration in experimental untrained group $\mathrm{EU}$
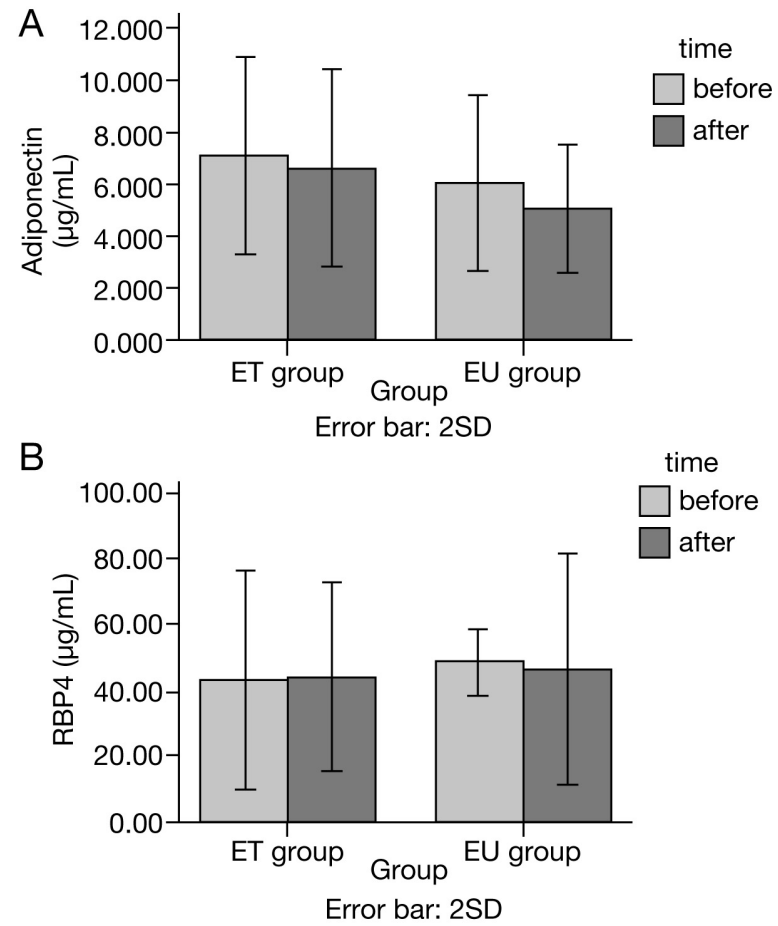

Fig. 1 Changes (mean \pm SD) in adiponectin (A) and RBP4 (B) levels before and after resistance training in experimental trained (ET) and experimental untrained (EU) groups, significant difference $(p<0.05)$ between adiponectin values within group (paired- sample $t$-test) before and after resistance training in EU group.

compared to the level of adiponectin in ET group (Fig. 1). ANOVA analysis, after exercise showed plasma glucose was the only variable which was significantly different between groups (Table 2) and subsequently 
Table 2 Clinical and metabolic markers after one session resistance training program in trained and untrained subgroups

\begin{tabular}{|c|c|c|c|c|c|}
\hline & \multicolumn{2}{|c|}{ Trained } & \multicolumn{2}{|c|}{ Untrained } & \multirow{2}{*}{$P$ value } \\
\hline & ET & CT & EU & $\mathrm{CU}$ & \\
\hline Glucose (mg/dL) & $84.00 \pm 7.64$ & $101 \pm 16.58$ & $96.87 \pm 11.02$ & $94.14 \pm 10.25$ & $0.021 *$ \\
\hline Insulin (mU/L) & $20.37 \pm 8.27$ & $22.76 \pm 13.84$ & $35.42 \pm 37.25$ & $14.55 \pm 6.43$ & 0.23 \\
\hline Triglyceride (mg/dL) & $182.3 \pm 50.08$ & $204 \pm 131.98$ & $184 \pm 32.19$ & $156.85 \pm 47.94$ & 0.69 \\
\hline Total Cholesterol (mg/dL) & $156.90 \pm 27.27$ & $152.33 \pm 19.67$ & $138.37 \pm 24.21$ & $150.28 \pm 28.25$ & 0.47 \\
\hline HDL Cholesterol (mg/dL) & $38.6 \pm 9.5$ & $36.2 \pm 4.8$ & $34.5 \pm 3.2$ & $38.1 \pm 7.2$ & 0.59 \\
\hline LDL Cholesterol (mg/dL) & $75.7 \pm 17.1$ & $78.0 \pm 16.62$ & $73.62 \pm 18.39$ & $81.71 \pm 20.06$ & 0.28 \\
\hline $\mathrm{RBP} 4(\mu \mathrm{g} / \mathrm{mL})$ & $44 \pm 14.36$ & $41 \pm 26.63$ & $46.50 \pm 17.62$ & $42.85 \pm 19.00$ & 0.95 \\
\hline Adiponectin $(\mu \mathrm{g} / \mathrm{mL})$ & $6.58 \pm 1.91$ & $5.33 \pm 3.07$ & $5.05 \pm 1.22$ & $5.91 \pm 2.36$ & 0.49 \\
\hline CRP (mg/L) & $0.20 \pm 0.16$ & $0.96 \pm 1.58$ & $0.53 \pm 0.60$ & $0.17 \pm 0.95$ & 0.21 \\
\hline
\end{tabular}

ET, experimental trained; CT, control trained; EU, experimental untrained; CU,control untrained. RBP4, retinol binding protein4, CRP, C-reactive protein. Values are expressed as mean $\pm S D$. Comparison between groups was performed by analysis of variance (ANOVA). ${ }^{*} P<0.05$ indicates significant differences between groups. No differences between groups for retinol -binding protein-4, adiponectin and CRP measured.

Table 3 Relationship between after exercise Adiponectin and RBP4 with different predictors Based on Linear regression Model

\begin{tabular}{|c|c|c|c|c|c|c|c|c|}
\hline \multirow{3}{*}{ Predictors } & \multicolumn{4}{|c|}{ Adiponectin } & \multicolumn{4}{|c|}{ RBP4 } \\
\hline & univariate & model & multivariate & model & univariate & model & multivariate & model \\
\hline & $\begin{array}{l}\text { standardized } \\
\beta \text { coefficient } \\
\end{array}$ & $P$ value & $\begin{array}{l}\text { standardized } \\
\beta \text { coefficient }\end{array}$ & $P$ value & $\begin{array}{l}\text { standardized } \\
\beta \text { coefficient }\end{array}$ & $P$ value & $\begin{array}{l}\text { standardized } \\
\beta \text { coefficient }\end{array}$ & $P$ value \\
\hline$\overline{\mathrm{PHT}}$ & 0.12 & 0.50 & - & - & -0.06 & 0.76 & - & - \\
\hline ARE & 0.07 & 0.69 & - & - & 0.08 & 0.64 & - & - \\
\hline Age & 0.11 & 0.54 & - & - & 0.23 & 0.19 & 0.07 & 0.6 \\
\hline BMI & 0.13 & 0.46 & - & - & 0.22 & 0.18 & 0.11 & 0.5 \\
\hline Glucose & 0.08 & 0.65 & - & - & -0.14 & 0.41 & - & - \\
\hline Insulin & -0.21 & 0.23 & - & - & -0.05 & 0.75 & - & - \\
\hline Triglyceride & -0.29 & 0.10 & 0.05 & 0.74 & 0.07 & 0.65 & - & - \\
\hline Total Cholesterol & 0.13 & 0.47 & - & - & 0.13 & 0.47 & - & - \\
\hline HDL Cholesterol & 0.44 & $0.01^{*}$ & 0.27 & $0.09 *$ & -0.19 & 0.27 & - & - \\
\hline LDL Cholesterol & 0.07 & 0.70 & - & - & 0.15 & 0.4 & - & - \\
\hline CRP & 0.29 & 0.10 & 0.16 & 0.22 & -0.05 & 0.95 & - & - \\
\hline Basal RBP4 & 0.52 & $0.002 *$ & 0.01 & 0.9 & 0.52 & $0.002 *$ & 0.46 & $0.01^{*}$ \\
\hline Basal Adiponectin & 0.68 & $<0.001^{*}$ & 0.5 & $0.00 *$ & -0.024 & $<0.001 *$ & -0.03 & 0.8 \\
\hline
\end{tabular}

PHT; past history of resistance training, ARE; acute resistance exercise session, BMI; body mass index, CRP; C-reactive protein, RBP4; retinol binding protein 4. *significant independent determinant of after exercise adiponectin and RBP4

the Scheffe post-hoc test showed this difference was related to CU group. Physical activity and one session acute exercise were considered as quantitative variables and entered to univariate regression analysis model as well as other variables. We found that, after exercise serum concentration of adiponectin were negatively correlated with basal RBP4 (standardized $\beta$ coefficient $=-0.36, p=0.32)$ and TG $(\beta=-0.28, p=0.10)$ and positively correlated with basic level of adiponectin $(\beta=0.68, p<0.001)$, HDL ( $\beta=0.43, p=0.01$ ) (Table $3)$. Post exercise concentrations of RBP4 were neg- atively correlated with adiponectin $(\beta=-0.23, p=0.17)$ and positively correlated with basal RBP4 $(\beta=0.52$, $p=0.002)$, age $(\beta=0.22, p=0.19)$ and BMI $(\beta=-0.23$, $p=0.18$ ) (Table 3). Subsequent adjusted regression model showed, basal adiponectin and HDL cholesterol were the main predictors of post exercise adiponectin (Table 3). After performing the same analysis for RBP4 ,the result showed, age and body mass index (BMI) relationship were weaker and the basal RBP4 appeared to be only predictor of post exercise RBP4 concentration $(\beta=0.46, p=0.02)$ (Table 3). 


\section{Discussion}

We examined the ability of a single resistance training session to change adiponectin in trained and untrained young healthy male. Moreover this study is the first investigation comparing the effect of acute resistant exercise on RBP4 and CRP in trained and untrained young healthy male. In the baseline phase analysis of this study we didn't detect any significant differences in serum levels of adiponectin at baseline between trained and untrained individual. These finding confirmed those of Varady et al [13] who didn't detect significant differences in plasma adiponectin between trained and sedentary subjects at baseline and those of Perseghin et al who didn't detect any differences in plasma adiponectin [14] between marathon runner and lean sedentary individual matched for BMI. A novel finding of this study was that, the basic level of RBP4 and CRP also didn't differ between trained and untrained groups.

The present study demonstrated that after exercise adiponectin and RBP4 concentration would not be influenced by having history of regular training. The result of our study is in accordance with the conclusion of previous studies reporting long term training has no effect on basal plasma adiponectin concentration in healthy subjects [15-17]. In line with this evidence some studies reported that prolonged exercise neither effect plasma adiponectin concentration nor expression of adiponectin receptors in healthy lean male [18-19]. While elevated plasma adiponectin concentration in overweight men [20] and in middle aged adult who were predispose to metabolic syndrome [21] were reported. There are a few studies which showed an increase in adiponectin in healthy non obese subjects following exercise, but even in these, the subjects were overweight inactive men and hyperlipidemic individual $[20,22]$. The results of studies of chronic RT intervention also reported that the adiponectin concentration tend to improve in overweight, obese or obese diabetic individual [23-25].

We found that, post exercise concentration of adiponectin was not affected by one session of acute resistance training. Actually research on the effect of acute resistance exercise on adiponectin level is limited. Our result inconsistent with the finding of the only available acute resistance study performed by Varady et al [13] that found increase in the level of adiponectin after acute strength training only in those who were habitual weight trainer. The basic levels of adiponectin in mentioned study didn't differ between weight trainers and sedentary similar to our finding. Since variability of results is dependent on the kind of analysis method used [26], we speculate using different statistical analysis methods, may be a reason for contradictory in our findings. The mentioned study which obtained significant changes in adiponectin concentration performed paired $t$ test. Actually many studies reported adiponectin changes in response to exercise used only intra-group ANOVA or $t$ test [27]. Using paired $t$ test, we also found that adiponectin levels significantly decreased in (EU) group, (data has not been shown), while comparing after exercise adipokines measures, between the 4 groups, we didn't find any significant differences. In the other hand, the different analysis method may induce distinct adiponectin responses even in a single study. Paired $t$ test focused on statistical differences between mean changes within a group before-after intervention. Weather finding a significant differences by this method is enough sensitive to be concluded to effectiveness of applied intervention and how much this significances are meaning full ,should be investigated later [28]. We preferred to use regression model (univariate and multivariate) to present our analysis for following reasons. First, this model has strong ability to find any relationship between variables and detect confounder effect. Second, the two variables, history of training and one session resistance exercise, were quantitative two-conditional variables and the third reason, was that, we had more than two studied groups. Taken together our regression model showed that after exercise adiponectin and RBP4 were not influenced by history of training and one session of acute resistance exercise. It is worth mentioning that, the serum half-life of RBP4 is about 10-12 hr and the sample was taken four hours after one session intervention in present study. Perhaps measuring the RBP4 closer to its half life would have given us more informative data in this regard.

Our study showed that the basic level of adiponectin was the strongest factor that determine after exercise adiponectin concentration. We suggest that exercise induced improvement in adiponectin could be influenced by the basic level of this adipokine. In our study the basic level of adiponectin explained $59 \%$ of post exercise adiponectin variances. The participant of the present study was young, healthy male and the mean plasma concentration of adiponectin in them was 
around 6.5 , no matter they trained or untrained. It is

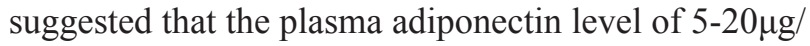
$\mathrm{mL}$ had significant inhibitory effects on inflammation and adiponectin concentration is decreased in low grade inflammation related disease such as obesity and type 2 diabetes [29-30]. Since levels of adiponectin is enough to maintain cardio metabolic health, adiponectin appears to remain unchanged following exercise in young, healthy normal weight individual [31]. However the result of other studies with contradictory finding $[13,32]$ could point at other mechanisms which regulate adiponectin secretion in response to exercise.

The fact that history of training shows no effect on adiponectin in our study might be related to the absence of low-grade systemic inflammation in our population. The low basic and unchanged post exercise level of CRP support this hypothesis. According to the literature low grade systemic inflammation is characterized by a two to there fold increase in the systemic concentration of cytokines such as CRP [33]. While the mean of CRP in all groups in this study were less than mg per litter. It seems, that the responses to an acute bout of RT in people with low grade inflammatory disease may differ from those in healthy individuals [34]. Our finding that indicates, adiponectin was not inversely related to CRP was in consistent with the previous study [35-36]. We suggest that in the absence of low grade inflammation, once CRP is not high, the inverse relationship between these does not exist any more. We also found that HDL cholesterol which in turn explained $28 \%$ of adiponectin variances level, was the second strong predictor of post exercise adiponectin concentration. The strongly and independently correlation of HDL cholesterol with adiponectin in present study is supported by previous finding [37-39].

Regarding to RBP4 no previous study have attempted to compare the baseline levels of this adi- pokine in response to resistance exercise in trained and untrained men. Furthermore acute exercise studies on RBP4 to date have used untrained subjects and aerobic exercise protocol. We found that the basic level of RBP4 was the only predictor of the after exercise plasma RBP4 concentration. This is further supported by the recent studies which showed that the effect of exercise seem to be more evident in those with high initial RBP4. In addition, RBP4 levels were decreased after exercise mainly in the subjects having higher level of RBP4 at baseline such as older people and type 2 diabetic patients [40-42].

One of our limitations was the small number of subjects in these study groups, however we used appropriate analysis method which could to overcome this limitation.

In conclusion, we found that the basic level of adiponectin and HDL cholesterol were two strong predictors of after exercise adiponectin concentration in healthy young men. Neither one session of acute resistance exercise nor long term training had predicting effect on post exercise adiponectin and RBP4 concentration. In the other hand, the beneficial effect of acute resistance exercise training may not be reflected by changes in adiponectin and RBP4 concentration in trained and untrained healthy young individual.

\section{Conflict of Interest Statement}

Authors are confident that they are not affected by conflicts of interest.

\section{Acknowledgment}

This research has been supported by the Endocrinology Metabolism Research Center of Tehran University of Medical Sciences, Tehran, and I.R. Iran.

\section{References}

1. Lavie CJ, Thomas RJ, Squires RW, Allison TG, Milani RV (2009) Exercise training and cardiac rehabilitation in primary and secondary prevention of coronary heart disease. Mayo Clin Proc 84(4): 373-383.

2. Laukkanen JA, Kurl S, Salonen JT (2002) cardiorespiratory fitness and physical activity as risk predictors of future atherosclerotic cardiovascular diseases. Curr Atheroscler Rep 4(6): 468-476.

3. Thompson PD, Buchner D, Pina IL, Balady GJ, Williams
MA, Marcus BH, Berra K, Blair SN, Costa F, Franklin B, Fletcher GF, Gordon NF, Pate RR, Rodriguez BL, Yancey AK, Wenger NK (2003) Exercise and physical activity in the prevention and treatment of atherosclerotic cardiovascular disease. Circulation 107: 31093116.

4. Szmitko P E, Teoh H, Duncan J (2007) Adiponectin and cardiovascular disease: state of the art. Am J Physiol Heart Circ Physiol 292: H1655-H1663. 
5. Matsuzawa Y, Funahashi T, Nakamura T (1999) Molecular mechanism of metabolic syndrome $\mathrm{X}$ : Contribution of adipocytokines adipocyte-derived bioactive substances. Ann NY Acad Sci 892: 146-154.

6. Okamoto Y, Kihara S, Funahashi T, Matsuzawa Y, Libby P (2006) Adiponectin: a key adipocytokine in metabolic syndrome. Clin Sci (Lond) 110: 267-278.

7. Balagopal P, Graham TE, Kahn BB, Altomare A, Funanage V, George D (2007) Reduction of elevated serum retinol binding protein in obese children by lifestyle intervention: association with subclinical inflammation. J Clin Endocrinol Metab 92: 1971-1974.

8. Erikstrup C, Mortensen OH, Pedersen BK (2006) Retinol-binding protein 4 and insulin resistance. $N$ Engl J Med 355: 1393-1394.

9. Takebayashi K, Suetsugu M, Wakabayashi S, Aso Y, Inukai T (2007) Retinol binding protein-4 levels and clinical features of type 2 diabetes patients. J Clin Endocrinol Metab 92: 2712-2719.

10. Cho YM, Youn BS, Lee H, Lee N, Min SS, Kwak SH, Lee HK, Park KS (2006) Plasma retinol-binding protein-4 concentrations are elevated in human subjects with impaired glucose tolerance and type 2 diabetes. Diabetes Care 29: 2457-2461.

11. Ingelsson E, Sundström J, Melhus H, Michaëlsson K, Berne C, Vasan RS, Risérus U, Blomhoff R, Lind L, Ärnlöv J (2009) Circulating retinol-binding protein 4, cardiovascular risk factors and prevalent cardiovascular disease in elderly. Atherosclerosis 206:239-244.

12. Williams MA, Haskell WL, Ades PA, Amsterdam EA, Bittner V, Franklin BA, Gulanick M, Laing ST, Stewart KJ (2007) Resistance exercise in individuals with and without cardiovascular disease. Circulation 116(5):572584.

13. Varady K, Bhutani S, Church EC, Pilips SA (2010) Adipokine Responses to Acute Resistance Exercise in Trained and Untrained Men. Med Sci Sport Exer 42(3): 456-462.

14. Perseghin G, Burska A, Lattuada G, Alberti G, Costantino F, Ragogna F, Oggionni S, Scollo A, Terruzzi I, Luzi L (2006) Increased serum resistinin in elite endurance athletes with high insulin sensitivity. Diabetologia 49(8): 1893-1900.

15. Marcell TJ, McAuley KA, Traustadottir T, Reaven PD (2005) Exercise training is not associated with improved levels of C-reactive protein or adiponectin. Metabolism 54: 533-541.

16. Yatagai T, Nishida Y, Nagasaka S. Nakamura T, Tokuyama K, Shindo M, Tanaka H, Ishibashi S (2003) Relationship between exercise training-induced increase in insulin sensitivity and adiponectinemia in healthy men. Endocr J 50: 233-238.

17. Hulver MW, Zheng D, Tanner CJ, Houmard JA, Kraus WE, Slentz CA, Sinha MK, Pories WJ, MacDonald KG , Dohm GL (2002) Adiponectin is not altered with exercise training despite enhanced insulin action. Am J Physiol Endocrinol Metabol 283: E861-E865.

18. Punyadeera C, Zorenc A, Koopman R, McAinch AJ, \& Smit E (2005) The effects of exercise and adipose tissue lipolysis on plasma adiponectin concentration and adiponectin receptor expression in human skeletal muscle. Eur J Endocrinol 152: 427-436.

19. Bluher M, Bullen JW, Lee JH, Kralisch S, Fasshauer M, Kloting N, Niebauer J, Schon MR, Williams CJ Mantzoros CS (2006) Circulating adiponectin and expression of adiponectin receptors in human skeletal muscle: associations withmetabolic parameters and insulin resistance and regulation by physical training. $J$ Clinical Endocr Metab 91: 2310-2316.

20. Kriketos AD, Gan SK, Poynten AM, Furler SM, Chisholm DJ, Campbell L (2004) Exercise increases adiponectin levels and insulin sensitivity in humans. Diabetes Care 27: 629-630.

21. Ring-Dimitriou S, Paulweber B, von Duvillard SP, Stadlmann M, LeMura LM, Lang J , Müller E (2006) The effect of physical activity and physical fitness on plasma adiponectin in adults with predisposition to metabolic syndrome. Eur J Appl Physiol 98: 472-481.

22. Yoshida $H$, Ishikawa $T$, Suto $M$, Kurosawa H, Hirowatari Y, Ito K, Yanai H, Tada N, Suzuki M (2010) Effects of Supervised Aerobic Exercise training on serum adiponectin and Parammeters of Lipid and Glucose Metabolism in Subjects with Moderate Dyslipidemia. $J$ Atheroscler Thromb 17(11): 1160-1166.

23. Olson T, Dengel DR, Leon AS, Schmitz KH (2007) Changes in inflammatory biomarkers following oneyear of moderate resistance training in overweight women. Int J Obes 31: 996- 1003.

24. Ahmadizad S, Haghighi AH, Hamedinia MR (2007) Effects of resistance versus endurance training on serum adiponectin and insulin resistance index. Eur $J$ Endocrinol 157: 625-631.

25. Brooks N, Layne JE, Gordon PL, Roubenoff R, Nelson ME (2007) Strength training improves muscle quality and insulin sensitivity in Hispanic older adults with type 2 diabetes. Int J Med Sci 4: 19-27.

26. Cohen J (1977) Statistical power analyses for the behavioral science. Rev. ed. New York: Academic Press

27. Simpson KA, Fiatarone Singh MA (2008) Effects of Exercise on Adiponectin, A Systematic Review. Obesity 16: 241-256.

28. Middel B, Sonderen EV (2002) Statistical significant change versus relevant or important change in (quasi) experimental design. Some conceptual and methodological problems in estimating magnitude of interventionrelated change in health services research. Int J Integr Care 2: e15.

29. Calle MC, Fernandez ML (2010) Effects of resistant training on the inflammatory response. Nutr Res Pract 4(4): 259-269. 
30. Catalan V, Rodriguez A, Becerril S, Sáinz N, GómezAmbrosi J, Frühbeck G (2006) Adipopharmacology of inflammation and insulin resistance. Biomed Rev 17: 43-51.

31. Kraemer RR, Aboudehen KS, Carruth AK, Durand RJ, Acevedo EO, Hebert EP, Johnson LG, Castracane VD (2003) Adiponectin responses to continuous and progressively intense intermittent exercise. Med Sci Sports Exerc 35: 1320-1325.

32. Hara T, Fujiwara H, Nakao H, Mimura T, Yoshikawa T, Fujimoto S (2005) Body composition is related to increase in plasma adiponectin levels rather than training in young obese men. Eur J Appl Physiol 94 (5-6): 520-526.

33. Peterson IS, Pedereson BK (2005) The anti-inflammatory effect of exercise. J Appl Physiol 98: 1154-1162.

34. Ploeger HE, Takken T, Greef MH, Timmons BW (2009) The effects of acute and chronic exercise on inflammatory markers in children and adult with a chronic inflammatory disease . Exerc Immunol Rev 15: 6-41.

35. Matsubara M, Namioka K, Katayose S (2003) Decreased plasma adiponectin concentrations in women with low grade C-reactive protein elevation. Eur J Endocrinol 148: 657-662.

36. Ouchi N, Kihara S, Funahashi T, Nakamura T, Nishida M, Kumada M, Okamoto Y, Ohashi K, Nagaretani H, Kishida K, Nishizawa H, Maeda N, Kobayashi H, Hiraoka H, Matsuzawa Y (2003) Reciprocal association of C-reactive protein with adiponectin in blood stream and adipose tissue. Circulation 107: 671-674.
37. Martin LJ, Woo JG, Daniels SR, Goodman E, Dolan LM (2005) The relationships of adiponectin with insulin and lipids are strengthened with increasing adiposity. J Clin Endocrinol Metab 90: 4255-4259.

38. Côté M, Mauriège $\mathrm{P}$, Bergeron J, Alméras N, Tremblay A, Lemieux I, Després JP (2005) Adiponectinemia in visceral obesity: impact on glucose tolerance and plasma lipoprotein and lipid levels in men. J Clin Endocrinol Metab 90: 1434-1439.

39. Vergès B, Petit J M, Duvillard L, Dautin G, Florentin E, Galland F, Gambert F (2006) Adiponectin Is an Important Determinant of ApoA-I Catabolism. Arterioscler Thromb Vasc Biol 26: 1364-1369.

40. Graham TE, Yang Q, Bluher M, Hammarstedt A, Ciaraldi TP, Henry RR, Wason CJ, Oberbach A, Jansson PA, Smith U \& Kahn B (2006) Retinol-binding protein 4 and insulin resistance in lean, obese, and diabetic subjects. $N$ Engl J Med 354: 2552-2563.

41. Lim S, Choi SH, Jeong IK, Kim JH, Kim JH, Moon MK, Park KS, Lee HK, Kim YB, Jang HC (2008) Insulin-Sensitizing Effects of Exercise on Adiponectin and Retinol-Binding Protein-4 Concentrations in Young and Middle-Aged Women. J Clin Endocrinol Metab 93: 2263-2268.

42. Ku YH, Han KA, Ahn H, Kwon H, Koo BK, Kim HC, Min KW (2010) Resistance exercise did not alter intramuscular adipose tissue but reduced retinol-binding protein-4 concentration in individuals with type 2 diabetes mellitus. J Int Med Res 38(3): 782-791. 